\title{
Quality Control Analysis of The Water Meter Tools Using Decision-On-Belief Control Chart in PDAM Surya Sembada Surabaya
}

\author{
Farida Agustini Widjajati, Nuri Wahyuningsih and Lisda Septi Hasofah
}

\begin{abstract}
Efforts to maintain and improve the quality of the resulting product can be done by using statistical quality control. One of the methods used in quality control is DOB (Decision On Belief) control chart. DOB control chart is a controller diagram which is used in quality control of univariate data. In this paper, we discuss quality control of the water meter tools using DOB control chart. The case study is in PDAM Surya Sembada Surabaya. Production quality control can also be applied to the c univariate control chart to compute the sensitivity of DOB control chart. Implementation of c control chart and DOB control chart indicates that the data of water meter tools have not been statistically controlled. Application of DOB control chart provides results that are more sensitive by $\mathbf{2 3 . 3 3 \%}$ than c control chart based on the amount of data that is out of control.
\end{abstract}

Index Terms-C control chart, decision-on-belief control chart, quality control.

\section{INTRODUCTION}

$\mathbf{I}$ $\mathrm{N}$ the modern era, the development in trade, industry, and services that are supported by the development of science and technology encourages business towards free trade with tight competition. By considering the quality of products, the company's goal is to obtain optimal profits and at the same time be able to meet consumer demand on the quality of products and on competitive prices.

Perusahan Daerah Air Minum (PDAM) Surya Sembada Surabaya is a company owned by the local government in charge of satisfying water needs residents of Surabaya. Given the huge task, PDAM Surya Sembada Surabaya should be able to provide clean water, distribute clean water to the community, and provide satisfactory services to the community. Although PDAM Surya Sembada Surabaya has implemented quality management and in accordance with the standard guidelines, but in reality there is still water usage errors caused by the state of the water meter of released by the PDAM Surya Sembada Surabaya. In response to these problems, we need to apply appropriate quality control system with clear objectives and stages, as well as providing innovations in the prevention and solution of the problems faced by the company.

Statistical quality control is the use of statistical methods for collecting and analyzing data in determining and overseeing the product quality [1]. One of the tools often used in statistical quality control is control chart. There are two kinds of control

\footnotetext{
Manuscript received February 24, 2016; accepted February 28, 2016.

The authors are with the Department of Mathematics, Institut Teknologi Sepuluh Nopember, Surabaya 60111, Indonesia. Emails: farida@matematika.its.ac.id, nuri@matematika.its.ac.id
}

charts according to the quality type: characteristic variable control charts and attribute control charts [2]. In addition, according to the number of quality characteristics observed, control charts of attributes and variables can also be divided into two categories: univariate and multivariate control charts. One of the attributes of univariate control charts is a c control chart. $\mathrm{C}$ control charts are used in the analysis of the number of defects in the product units that remain.

There are several methods discussing the characteristics' quality. A new concept to analyze and classify the state of quality control system is using DOB (Decision On Belief) univariate attribute control charts [3]. DOB is a control chart based on Bayes' Theorem.

Based on this background and also [4], this paper investigates the classification of defects for the water meter tool at PDAM Surya Sembada Surabaya. We also study the most dominating type of disability, as well as identify the factors that cause these kinds of defects. Then we analyze quality control of the water meter tool using DOB control charts. Furthermore we also compare the sensitivity of DOB control chart and c univariate control chart. The comparison result is observed based on the amount of out of control data.

\section{Research Methodology}

\section{A. Research Sources}

We use a secondary data obtained from PDAM Surabaya Surya Sembada. The obtained data is in the form of quantitative and qualitative data. Quantitative data is a data in the form of figures on the number of replacement water meter tools in the period of April 2013 to September 2015 based on customer statements. Qualitative data is a data in the form of written information about the types of defects and cause of disability.

\section{B. Data Analysis Techniques}

The analysis techniques in this research are performed quantitatively using statistical approaches, in order to obtain accurate conclusions. We use one of the techniques in the analysis of quality control called DOB control charts. Furthermore this research uses a statistical software application called Minitab.

The steps used in this research is as follows:

1) Assess the control limit formulation of DOB control charts. 
2) Identify the number of each type of disability by using a check sheet. Sheet inspection or check sheet is a form which is designed to record data. Inspection sheet analysis helps to determine facts or patterns that may help in further analysis [5].

3) Make a histogram. The histogram shows a calculation of the value of coverage frequency of each occurred value. The histogram shows the most common events and also variations in the measurements [5].

4) Determine the priority repair (using Pareto diagram). Pareto diagram is a method for managing errors, problems, or disabilities to help focusing efforts on the problem resolution. After Pareto diagram is made then the next step is to find the cause of defective and look for ways to reduce the defective of the products [5].

5) Finding the dominant factors using the fishbone diagram. This diagram is a tool to get to know the process elements (causes) the possible effect on the outcomes. This diagram illustrates a diagram (shape resembles a fish bone) to the problem of quality control of day-to-day enterprise customers who are not satisfied. Each "bone" represents the source of errors [5].

6) Make recommendations/proposals to improve the quality.

7) Creating a c control chart. The charts are used to analyze the total number of mismatches. Suppose that a defective or not in accordance happens in this examination unit, then according to a Poisson distribution [6], we have

$$
p(x)=\frac{e^{-c} c^{x}}{x !}, \quad x=0,1,2, \ldots
$$

where $x$ represents the number of defectives and $c$ represents Poisson distribution parameter. Formulas for Upper Control Limits (UCL), Lower Control Limits (LCL), and Center Line (CL) for control charts $\mathrm{c}$ are as follows [6]:

$$
\begin{aligned}
U C L & =\bar{c}+3 \sqrt{\bar{c}} \\
C L & =\bar{c} \\
L C L & =\bar{c}-3 \sqrt{\bar{c}}
\end{aligned}
$$

where $\bar{c}=\frac{\sum c}{n}$ is the proportion of defects or nonconformities each subgroup, $\sum c$ is total defects or nonconformities each subgroup, $n$ is the amount of observation or number of subgroups.

8) Make DOB control charts. DOB control chart is a control chart that is used in quality control of the univariate data based on the total number of defectives [7]. The formula for the UCL and LCL DOB control charts are as follows:

$$
\begin{aligned}
& U C L_{B\left(x_{k}, O_{k-1}\right)}=\frac{e^{c \sqrt{k}}}{e^{c \sqrt{k}}+1} \\
& U C L_{B\left(x_{k}, O_{k-1}\right)}=\frac{e^{-c \sqrt{k}}}{e^{-c \sqrt{k}}+1}
\end{aligned}
$$

9) Comparing the output of $\mathrm{c}$ control charts and DOB control charts graphically to check the number of points that are outside the control limits.

\section{RESULTS AND Discussions}

\section{A. Control Limit of $\mathrm{DOB}$ Control Chart}

Suppose $O_{k}=\left(x_{1}, x_{2}, x_{3}, \ldots, x_{k}\right)$ be the vector of observations in the $k$-th iteration, where $x_{k}$ is the observation of a discrepancy in the number of inspected products. Then suppose $I$ as a state in control. After taking a new observation, $x_{k}$, we define probability on the state in control based on observation vector $O_{k-1}$ as follows

$$
\begin{aligned}
B\left(x_{k}, O_{k-1}\right) & =\operatorname{Pr}\left\{\text { in control } \mid x_{k}, O_{k-1}\right\} \\
& =\operatorname{Pr}\left\{I \mid x_{k}, O_{k-1}\right\}
\end{aligned}
$$

Suppose that $B\left(O_{k-1}\right)=B\left(x_{k-1}, O_{k-2}\right)$ as a previous observation that belongs to a state in-control, to renew $B\left(x_{k}, O_{k-1}\right)$, it is assumed that the observations are independent, thus $\operatorname{Pr}\left\{x_{k} \mid I, O_{k-1}\right\}=\operatorname{Pr}\left\{x_{k} \mid I\right\}$.

By using the Bayes' theorem and (7), we obtain

$$
\begin{aligned}
& B\left(x_{k} \mid O_{k-1}\right) \\
& =\operatorname{Pr}\left\{I \mid x_{k}, O_{k-1}\right\} \\
& =\frac{\operatorname{Pr}\left\{I, x_{k} \mid O_{k-1}\right\}}{\operatorname{Pr}\left\{x_{k}, O_{k-1}\right\}} \\
& =\frac{\operatorname{Pr}\left\{I \mid O_{k-1}\right\} \operatorname{Pr}\left\{x_{k} \mid I, O_{k-1}\right\}}{\operatorname{Pr}\left\{x_{k}, O_{k-1}\right\}} \\
& =\frac{\operatorname{Pr}\left\{I \mid O_{k-1}\right\} \operatorname{Pr}\left\{x_{k} \mid I\right\}}{\operatorname{Pr}\left\{I \mid O_{k-1}\right\} \operatorname{Pr}\left\{x_{k} \mid I\right\}+\operatorname{Pr}\left\{I^{c} \mid O_{k-1}\right\} \operatorname{Pr}\left\{x_{k} \mid I^{c}\right\}} \\
& =\frac{B\left(O_{k-1}\right) \operatorname{Pr}\left\{x_{k} \mid I\right\}}{B\left(O_{k-1}\right) \operatorname{Pr}\left\{x_{k} \mid I\right\}+\left(1-B\left(O_{k-1}\right)\right) \operatorname{Pr}\left\{x_{k} \mid I^{c}\right\}}
\end{aligned}
$$

Then we define

$$
\operatorname{Pr}\left\{x_{k} \mid I\right\}=e^{\frac{x_{k}-\mu_{0}}{\sigma_{0}}}
$$

and

$$
\operatorname{Pr}\left\{x_{k} \mid I^{c}\right\}=\phi\left(x_{k}\right)
$$

where $\phi\left(x_{k}\right)$ is a probability density function of the normal distribution with mean $\mu$ and variance $\sigma^{2}$. Thus (10) becomes

$$
\operatorname{Pr}\left\{x_{k} \mid I^{c}\right\}=1
$$

Substituting (9) and (11) into (8), we obtain

$$
B\left(x_{k}, O_{k-1}\right)=\frac{B\left(O_{k-1}\right) e^{\frac{x_{k}-\mu_{0}}{\sigma_{0}}}}{B\left(O_{k-1}\right) e^{\frac{x_{k}-\mu_{0}}{\sigma_{0}}}+\left(1-B\left(O_{k-1}\right)\right)}
$$

In order to calculate control limits, we define statistic $Z_{k}$ as follows

$$
Z_{k}=\frac{B\left(x_{k}, O_{k-1}\right)}{1-B\left(x_{k}, O_{k-1}\right)}=\frac{B\left(O_{k}\right)}{1-B\left(O_{k}\right)}
$$

Then (12) is substituted into (13), which yield

$$
\begin{aligned}
Z_{k} & =\frac{\left(\frac{B\left(O_{k-1}\right) e^{\frac{x_{k}-\mu_{0}}{\sigma_{0}}}}{B\left(O_{k-1}\right) e^{\frac{x_{k}-\mu_{0}}{\sigma_{0}}}+\left(1-B\left(O_{k-1}\right)\right)}\right)}{\left(1-\frac{B\left(O_{k-1}\right) e^{\frac{x_{k}-\mu_{0}}{\sigma_{0}}}}{B\left(O_{k-1}\right) e^{\frac{x_{k}-\mu_{0}}{\sigma_{0}}}+\left(1-B\left(O_{k-1}\right)\right)}\right)} \\
& =\frac{B\left(O_{k-1}\right) e^{\frac{x_{k}-\mu_{0}}{\sigma_{0}}}}{1-B\left(O_{k-1}\right)}
\end{aligned}
$$


For $k-1$ in (13), we obtain $Z_{k-1}=\frac{B\left(O_{k-1}\right)}{1-B\left(O_{k-1}\right)}$, thus (14) becomes

$$
Z_{k}=e^{\frac{x_{k}-\mu_{0}}{\sigma_{0}}} Z_{k-1}
$$

Then we construct a recurrence formula from (15) as follows

$$
\begin{aligned}
Z_{k} & =e^{\frac{x_{k}-\mu_{0}}{\sigma_{0}}} e^{\frac{x_{k-1}-\mu_{0}}{\sigma_{0}}} Z_{k-2}=\ldots \\
& =e^{\frac{\sum_{i=1}^{k} x_{i}-k \mu_{0}}{\sigma_{0}}}
\end{aligned}
$$

To eliminate the exponential form, (16) is simplified to

$$
\ln \left(Z_{k}\right)=\frac{\sum_{i=1}^{k} x_{i}-k \mu_{0}}{\sigma_{0}}
$$

The initial value of $Z_{0}$ and $B\left(O_{0}\right)$ for $k=1$ in (17) is

$$
Z_{1}=e^{\frac{\sum_{i=1}^{1} x_{i}-\mu_{0}}{\sigma_{0}}}=e^{\frac{x_{1}-\mu_{0}}{\sigma_{0}}}
$$

From (15), we know that

$$
Z_{1}=e^{\frac{x_{1}-\mu_{0}}{\sigma_{0}}} Z_{0}
$$

which implies that $Z_{0}=1$. Furthermore the initial value of $B\left(O_{0}\right)$ is 0.5 .

According to (17), the mean value of $\ln \left(Z_{k}\right)$ is 0 and the variance is $k$, thus $\ln \left(Z_{k}\right) \approx N(0, k)$. Then we define UCL and LCL of Shewhart's control chart models for $\ln \left(Z_{k}\right)$ as follows

$$
U C L_{\ln \left(Z_{k}\right)}=\mu+c \sigma=c \sqrt{k}
$$

and

$$
L C L_{\ln \left(Z_{k}\right)}=\mu-c \sigma=-c \sqrt{k}
$$

where $c$ is a multiple of standard deviation of $\ln \left(Z_{k}\right)$ and determined such that if the the type-I error probability $\alpha$, then we obtain

$$
\operatorname{Pr}\left\{-c \sqrt{k} \leq \ln \left(Z_{k}\right) \leq c \sqrt{k}\right\}=1-\alpha
$$

To determine the value of control limits from statistical recursive $B\left(x_{k}, O_{k-1}\right)$, in this case $B\left(x_{k}, O_{k-1}\right)$ is used as a substitute, namely by substituting (13) to (20), as follows

$$
\operatorname{Pr}\left\{-c \sqrt{k} \leq \ln \left(\frac{B\left(x_{k}, O_{k-1}\right)}{1-B\left(x_{k}, O_{k-1}\right)}\right) \leq c \sqrt{k}\right\}=1-\alpha
$$

or

$$
\operatorname{Pr}\left\{e^{-c \sqrt{k}} \leq \frac{B\left(x_{k}, O_{k-1}\right)}{1-B\left(x_{k}, O_{k-1}\right)} \leq e^{c \sqrt{k}}\right\}=1-\alpha
$$

which means that

$$
\begin{array}{r}
\operatorname{Pr}\left\{e^{-c \sqrt{k}}+1 \leq \frac{B\left(x_{k}, O_{k-1}\right)}{1-B\left(x_{k}, O_{k-1}\right)}+1 \leq e^{c \sqrt{k}}+1\right\}=1-\alpha \\
\operatorname{Pr}\left\{e^{-c \sqrt{k}}+1 \leq \frac{1}{1-B\left(x_{k}, O_{k-1}\right)} \leq e^{c \sqrt{k}}+1\right\}=1-\alpha \\
\operatorname{Pr}\left\{\frac{1}{e^{-c \sqrt{k}}+1} \geq 1-B\left(x_{k}, O_{k-1}\right) \geq \frac{1}{e^{c \sqrt{k}}+1}\right\}=1-\alpha
\end{array}
$$

Then (23) is multiplied by -1 , which yield

$$
\operatorname{Pr}\left\{\frac{-1}{e^{-c \sqrt{k}}+1} \leq B\left(x_{k}, O_{k-1}\right)-1 \leq \frac{-1}{e^{c \sqrt{k}}+1}\right\}=1-\alpha
$$

$\operatorname{Pr}\left\{\frac{-1}{e^{-c \sqrt{k}}+1}+1 \leq B\left(x_{k}, O_{k-1}\right)-1+1 \leq \frac{-1}{e^{c \sqrt{k}}+1}+1\right\}=1-\alpha$

Thus the confidence interval $(1-\alpha) 100 \%$ for $B\left(x_{k}, O_{k-1}\right)$ is as follows

$$
\operatorname{Pr}\left\{\frac{e^{-c \sqrt{k}}}{e^{-c \sqrt{k}}+1} \leq B\left(x_{k}, O_{k-1}\right) \leq \frac{e^{c \sqrt{k}}}{e^{\sqrt{k}}+1}\right\}=1-\alpha
$$

Then we obtain UCL and LCL for $B\left(x_{k}, O_{k-1}\right)$, as follows:

$$
\begin{gathered}
U C L_{B\left(x_{k}, O_{k-1}\right)}=\frac{e^{c \sqrt{k}}}{e^{c \sqrt{k}}+1} \\
L C L_{B\left(x_{k}, O_{k-1}\right)}=\frac{e^{-c \sqrt{k}}}{e^{-c \sqrt{k}}+1}
\end{gathered}
$$

\section{B. Check Sheet}

In conducting statistical quality control, the first step is constructing a check sheet. The check sheet can be seen in Table I.

TABLE I

DEFECTIVE DATA OF WATER METER TOOLS IN PDAM SURYA SEMBADA SURABAYA FROM APRIL 2013 UNTIL SEPTEMBER 2015.

\begin{tabular}{|c|c|}
\hline Defective Type & Total Defective \\
\hline Jammed & 18.103 \\
Opaque & 93 \\
Broken glass & 212 \\
Meter doubtful & 883 \\
Broken needle & 1.521 \\
\hline Total & 20.812 \\
\hline
\end{tabular}

\section{Histogram}

From the histogram in Fig. 1, the most frequent defect is jammed with 18.103 occurrences. The number of defects due to broken needle is 1.521 pieces. Finally the type of disabilities due to meter doubtful, broken glass, and opaque is consecutively numbered $883,212,93$ pieces.

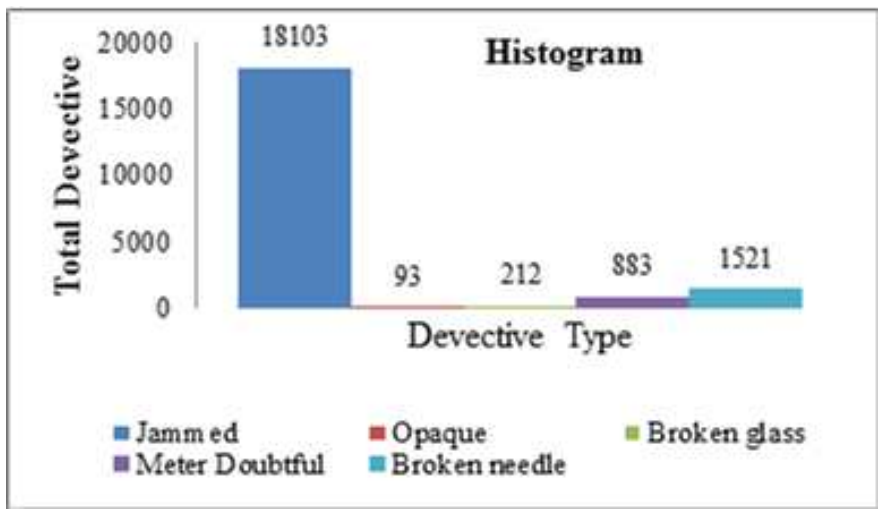

Fig. 1. Histogram plot of defective of water meter tools in PDAM Surya Sembada Surabaya from April 2013 to September 2015. 


\section{Pareto Diagram}

Figure 2 shows the defective was dominated by jammed type. The remaining defectives are due to broken needle $7.3 \%$, doubted meter by $4.2 \%$, broken glass by $1 \%$ and opaque by $0.4 \%$. Thus the repair can focus on the defects due to jammed. This is because jammed dominates $87 \%$ of the total defective in PDAM Surya Sembada Surabaya.

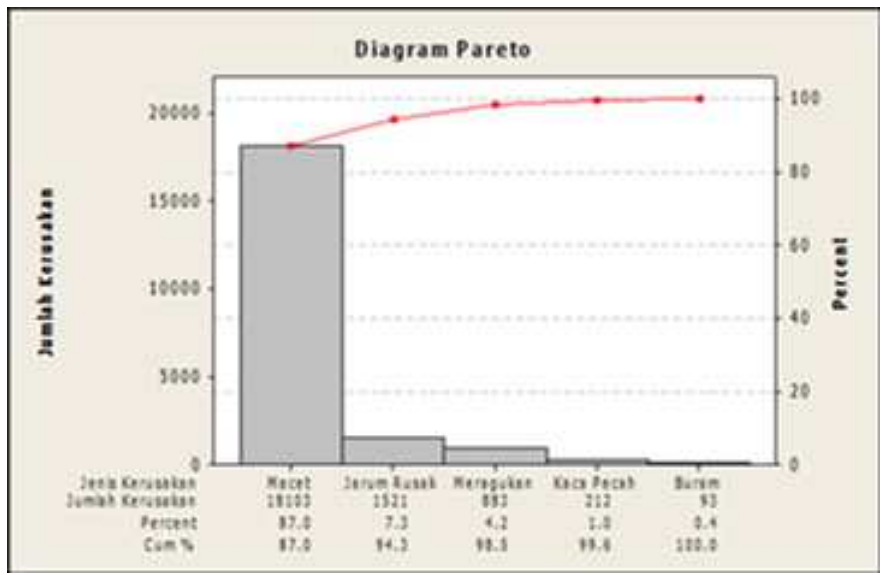

Fig. 2. Pareto diagram of defective water meter tools in PDAM Surya Sembada Surabaya from April 2013 until September 2015.

\section{E. Fishbone Diagram}

In this section, we use fishbone diagram to investigate each defect: jammed (see Fig. 3), opaque (see Fig. 4), broken glass (see Fig. 5), meter doubtful (see Fig. 6) and broken needle (see Fig. 7), as follows:

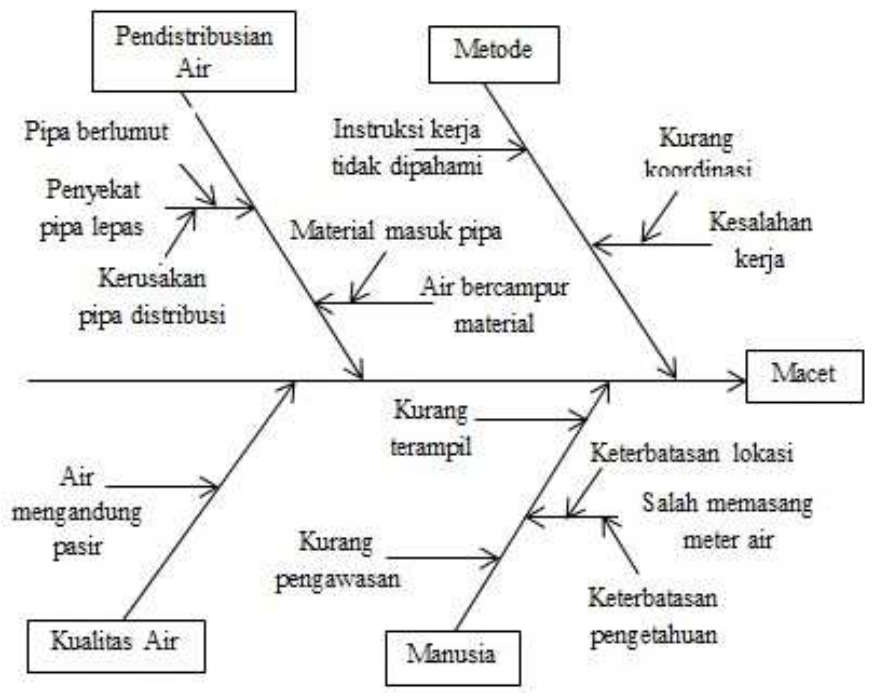

Fig. 3. Fishbone diagram for defective of the type jammed.

\section{F. Proposed Quality Improvement}

After knowing the cause of defects of the water meter tools that occurred in the PDAM Surya Sembada Surabaya, then we formulate a recommendation or a proposal of corrective

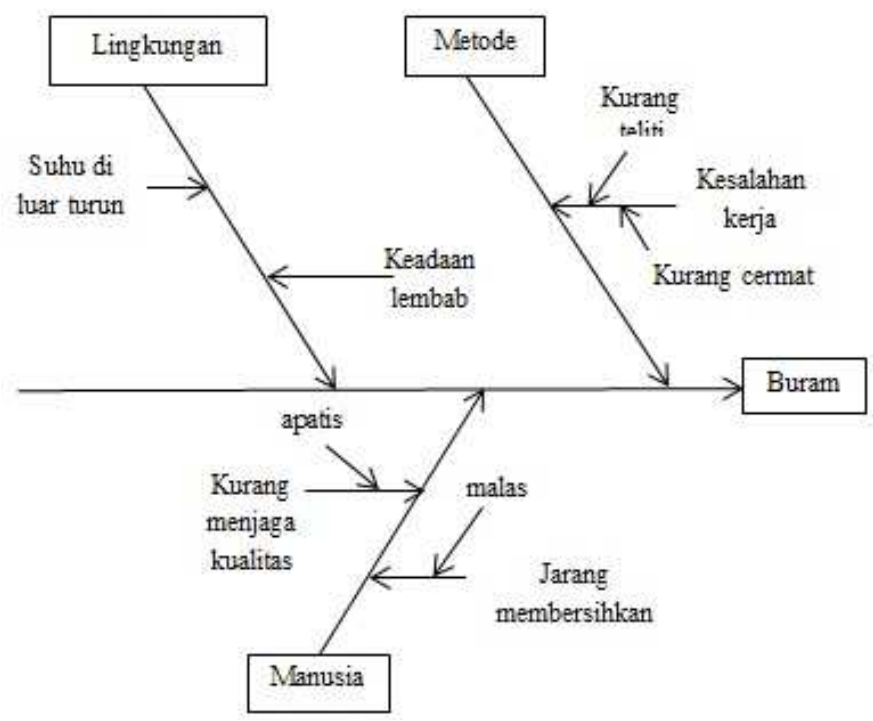

Fig. 4. Fishbone diagram for defective of the type opaque.

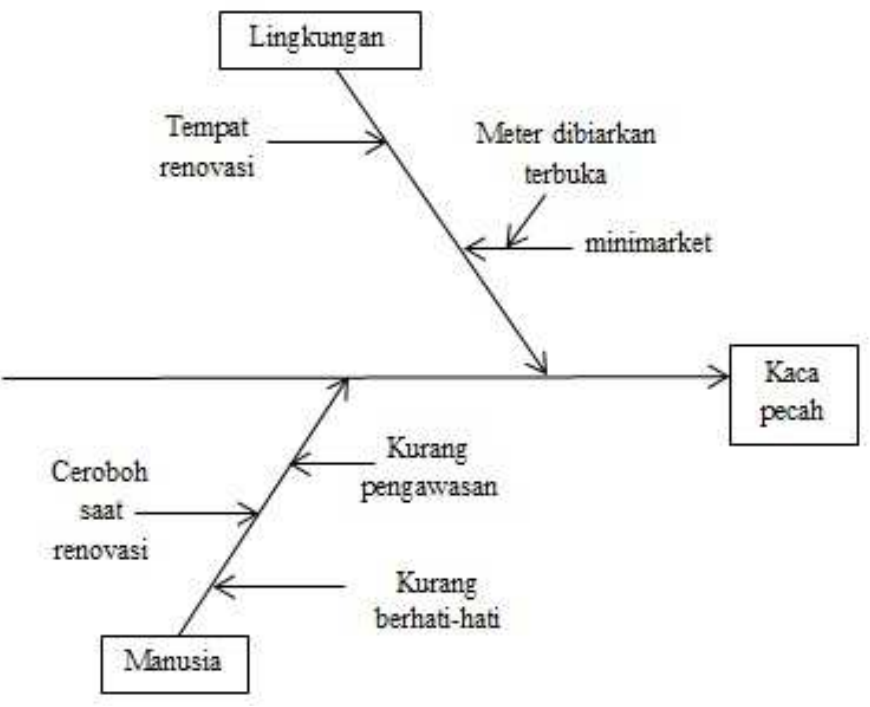

Fig. 5. Fishbone diagram for defective of the type broken glass.

actions in an effort to minimize the extent of defective to the products, as follows:

1) To check the pipes' distribution regularly, i.e. not only when the pipe is defective, in order to reduce the level of defects to the pipe so that the water distribution is not disturbed.

2) Conducting training programs on water tool meter installation for both old and new officers on a regular basis in order to avoid another mistake when installing water meter tools.

3) Work instructions are given in writing, accompanied by a detailed verbal explanation to carry out regular briefing at the beginning and end of the work.

4) Provide guidance to customers in order to perform maintenance on water meter tool routinely.

5) Creating a new work piece which is in charge of 


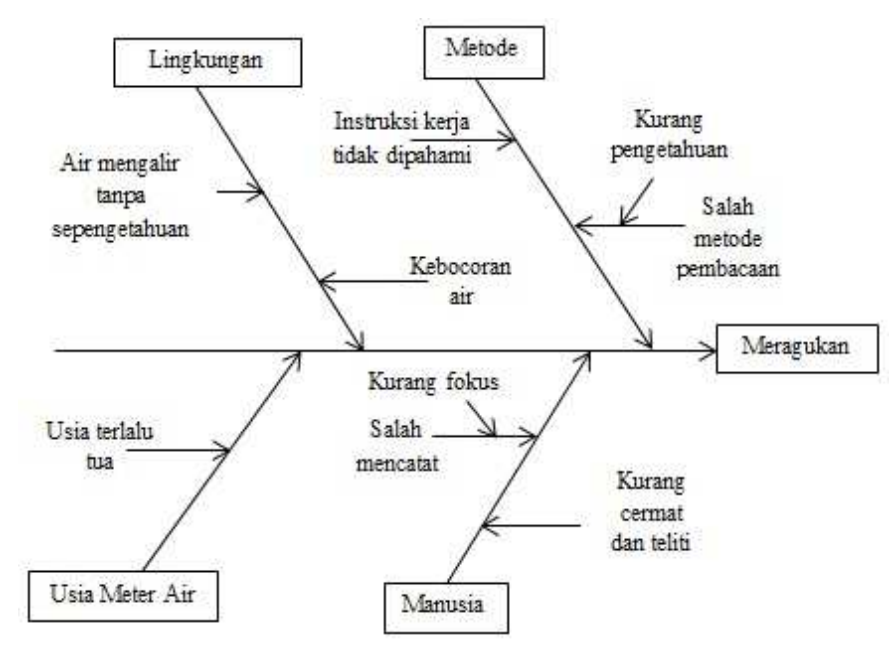

Fig. 6. Fishbone diagram for defective of the type meter doubtful.

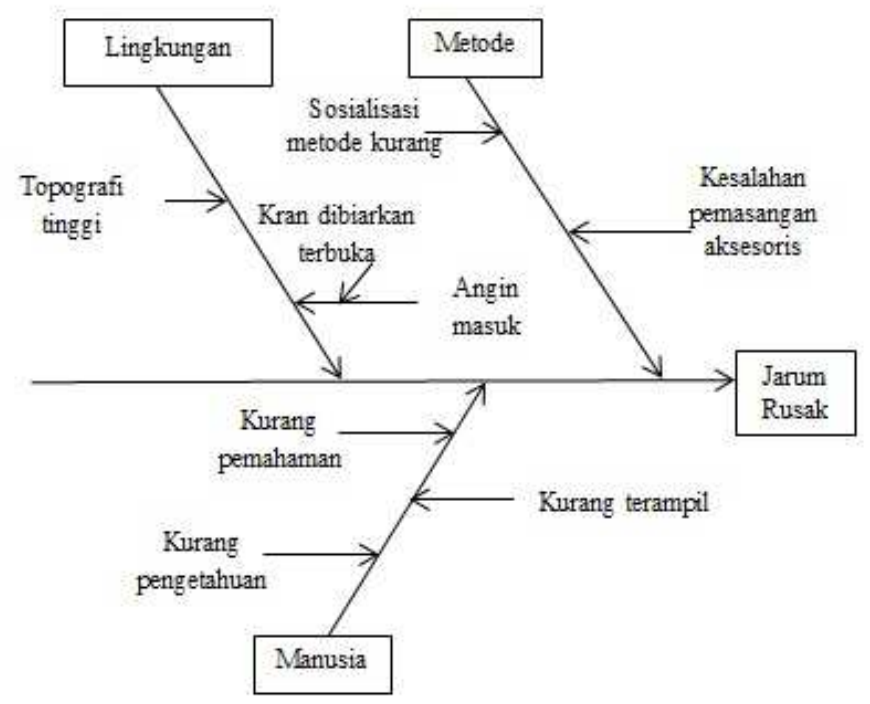

Fig. 7. Fishbone diagram for defective of the type broken needle.

supervising and double check the performance of the registrar of the water meter so it can reduce the water meter recording errors. Impose sanctions on officials who are failed to avoid failures that may occur later in life.

6) Directing more often to the clerk accessories, a water meter tool installer that works well.

\section{G. Analysis using the C Control Chart}

Quality control in water meter tool using c control charts is done to identify and determine the extent and type of defectives in the final product that can still be tolerated or not and still meet the criteria of control limits or not. After the calculations, the UCL is amounted to $772.7, \mathrm{LCL}$ is amounted to 614.7, and CL is amounted to 693.7. The C control charts are shown in Fig. 8.

Based on Fig. 8, it can be seen that there are 9 points that are outside the UCL 2, 3, 6, 7, 11, 12, 19, 25, 26 and there

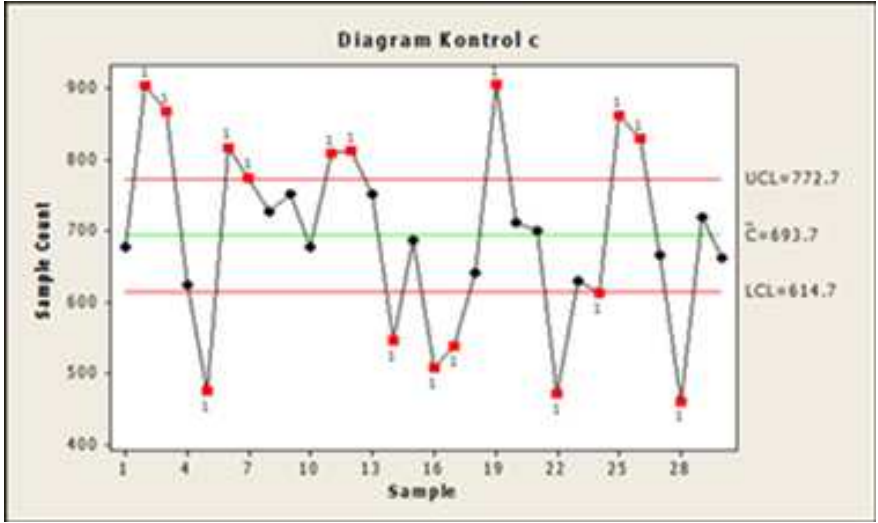

Fig. 8. C control chart.

are seven points that are outside LCL 5, 14, 16, 17, 22, 24, 28 . Thus the water meter has not been controlled statistically.

\section{H. Analysis using the DOB Control Chart}

Quality control in water meter tool using DOB control charts is done to compare with the c control chart, in order to decide which one is more sensitive. The steps to create DOB control charts are first searching for the value of each statistic $B\left(O_{k}\right)$, of each subgroup based on the equation (7). In this case, the value of each statistic $B\left(O_{k}\right)$ is interrelated, that is the value of statistics $B\left(O_{0}\right)$ is required to find the value of statistics $B\left(O_{1}\right)$, statistical value $B\left(O_{1}\right)$ is required to find the value of statistics $B\left(O_{2}\right)$, and so on to obtain a value of statistics $B\left(O_{29}\right)$.

The first plot point is equal to the value $B\left(O_{0}\right)$ in the early stages of 0.5 . Then for the calculation of the second plot point that is the value of statistics $B\left(O_{1}\right)$ up to the 30th plot point that is the statistical value $B\left(O_{29}\right)$ is described as follows.

$$
\begin{aligned}
B\left(O_{1}\right) & =\frac{B\left(O_{0}\right) e^{\frac{x_{1}-\mu_{0}}{\sigma_{0}}}}{B\left(O_{0}\right) e^{\frac{x_{1}-\mu_{0}}{\sigma_{0}}}+\left(1-B\left(O_{0}\right)\right)} \\
& =\frac{(0.5) e^{\frac{678-693.7}{26.34}}}{(0.5) e^{\frac{678-6933.7}{26.34}}+(1-0.5)} \\
& =0.355247537 \\
\vdots & \\
B\left(O_{28}\right) & =0.569776482 \\
B\left(O_{29}\right) & =0.775817279
\end{aligned}
$$

Having obtained the value of statistics $B\left(O_{k}\right)$, the next step is to find the UCL and LCL of DOB control charts. Then it is presented by using the DOB control chart, as shown in Fig. 9.

Based on Fig. 9, there are 23 points that are outside UCL thus the water meter tool has not been controlled statistically.

\section{Comparison between $C$ and DOB Control Chart Output}

Based on Table II, the quality control of the water meter tool using c control charts produces the 16 out of control data, while the application of DOB control charts produces 23 out 


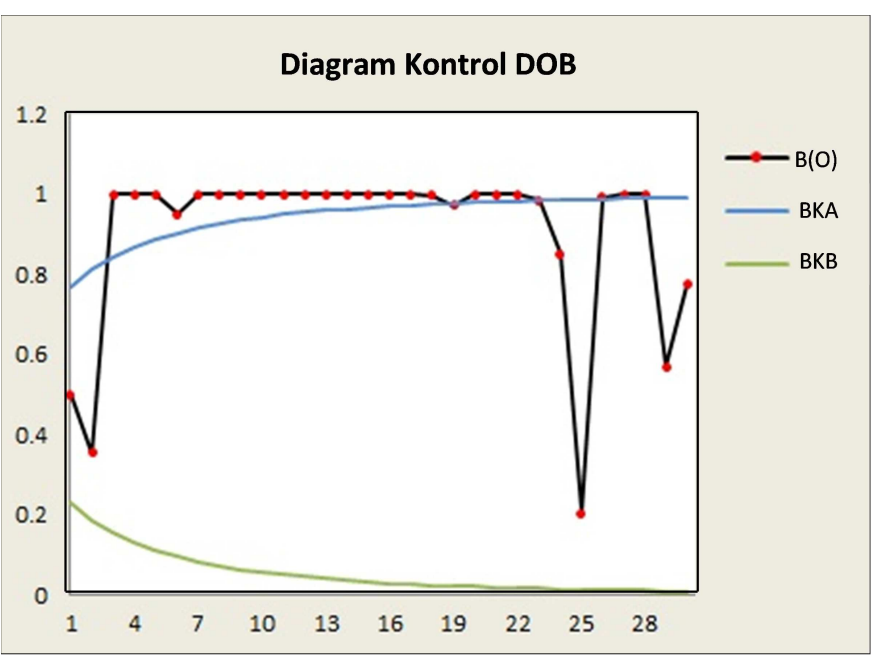

Fig. 9. DOB control chart.

of control data. Thus the $\mathrm{C}$ control chart capabilities are tend to be less sensitive in detecting the out of control data than a DOB control chart because c control chart generates more out of control data. Thus, the control charts are more precise than DOB in the process of quality control of the water meter tool at PDAM Surya Sembada Surabaya.

TABLE II

COMPARISON OF THE AMOUNT OF DATA THAT IS OUT OF CONTROL.

\begin{tabular}{|c|c|c|}
\hline Control chart & Total out of control & Percentage \\
\hline c & 16 & $53.33 \%$ \\
DOB & 23 & $76.66 \%$ \\
\hline
\end{tabular}

To check the sensitivity DOB control charts, other than by comparing the amount of out of control data, we can also use the following steps. The first step is to create a c control chart second stage. In this control chart, 16 out of control data as the data for the subgroup to 2, 3, 6 are eliminated. Thus the remaining subgroups are 14 subgroups. As can be seen in Fig. 10, the value of the control limits is changed due to the removal of 16 observation points (out of the control data). In this case, the UCL is amounted to 766.1, the LCL is amounted to 608.8 , and the $\mathrm{CL}$ is amounted to 687.4 .

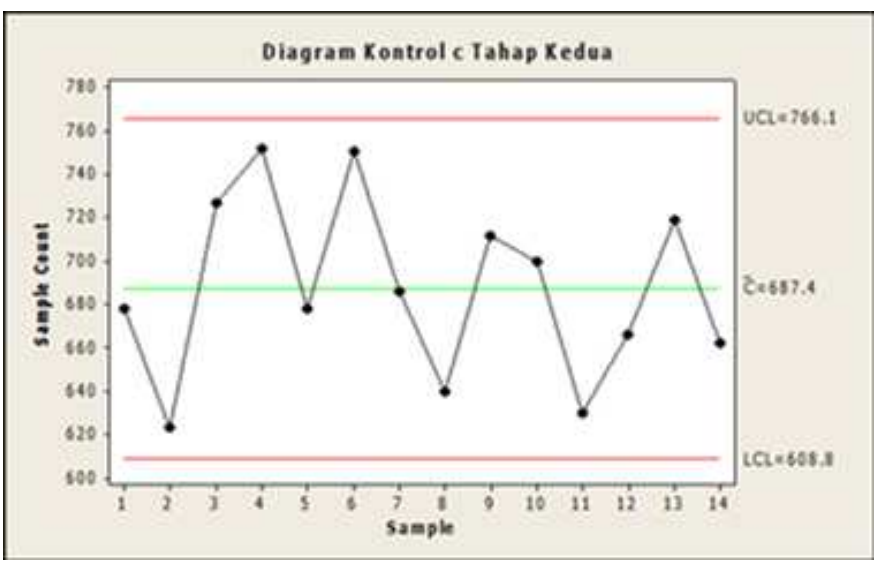

Fig. 10. C control chart: second stage.
Based on Fig. 10, notice that there are no observation points that are outside of the UCL and LCL. In other words, the control process water meter tool has been controlled statistically.

The next step is creating DOB control chart using data from 14 subgroups. First plot point is equal to the value $B\left(O_{0}\right)$ in the early stages of 0.5 . Then for the calculation of the second plot point, that is the statistical value $B\left(O_{1}\right)$, up to the 14 th plot point, that is the statistical value $B\left(O_{13}\right)$, is described as follows.

$$
\begin{aligned}
B\left(O_{1}\right) & =\frac{B\left(O_{0}\right) e^{\frac{x_{1}-\mu_{0}}{\sigma_{0}}}}{B\left(O_{0}\right) e^{\frac{x_{1}-\mu_{0}}{\sigma_{0}}+\left(1-B\left(O_{0}\right)\right)}} \\
& =\frac{(0.5) e^{\frac{678-687.4}{26.22}}}{(0.5) e^{\frac{678-687.4}{26.22}+(1-0.5)}} \\
& =0.411321522 \\
\vdots & \\
B\left(O_{12}\right) & =0.444923104 \\
B\left(O_{13}\right) & =0.727897557
\end{aligned}
$$

Based on Fig. 11, there are two points that are outside the UCL (the sub-group 7 and 8), with the value of 0.961821069 and 0.959811278 . Additionally, there is one point which is beyond LCL (the sub group to 3 ) with a value of 0.056537883 . In other words, the quality control process water meter using DOB control charts is not statistically controlled yet.

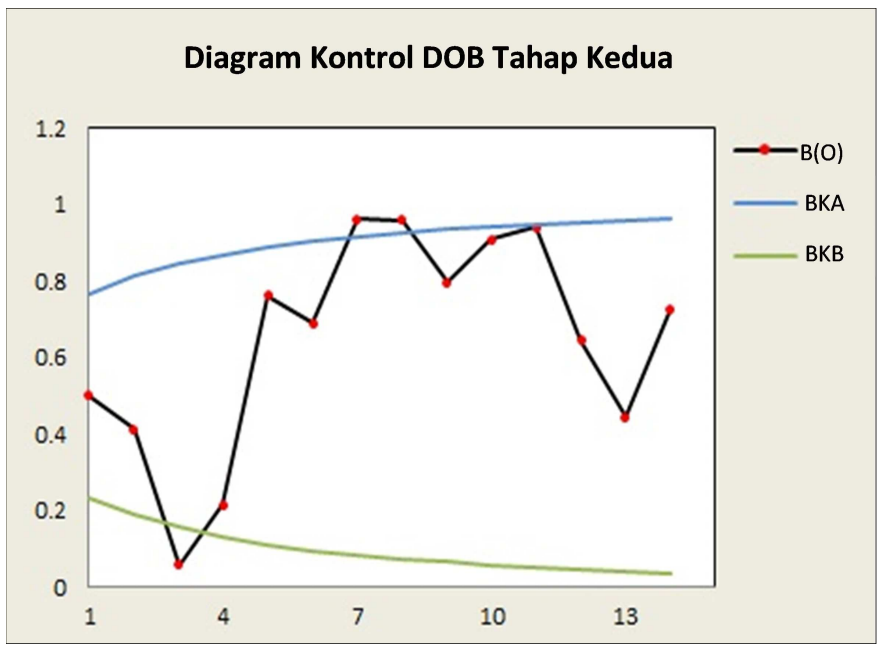

Fig. 11. DOB control chart: second stage.

It is used as a benchmark for comparison of the sensitivity of the methods of quality control statistical using $\mathrm{c}$ control charts and DOB control charts. In the c control chart, quality control process of the water meter has been controlled statistically since no data is out of control, while in the DOB control chart quality control process of the water meter tool has not been controlled statistically because there are three observation points that are outside the control limits. Thus, it can be concluded that the statistical quality control using DOB control charts is more sensitive compared to the c control chart in process quality control of the water meter tool in the PDAM Surya Sembada Surabaya. 


\section{Conclusions}

The results of the analysis and discussion that has been done in this paper can be summarized as follows:

1) To obtain the control limit of DOB control charts, outlined $B\left(x_{k}, O_{k-1}\right)$ which is the probability that the state is in control using Bayes' theorem.

2) Based on the analysis of cause and effect diagram (fishbone diagram), we can determine the factors causing defective to the meter of water that comes from work instructions that are not understood, faulty work, lack of supervision, the age of the water meter is too old, the lack of concerns in maintaining the cleanliness of the water meter, recording errors, and less socialization methods.

3) By using c control charts and DOB control charts in quality control of the meter water tool at PDAM Surya Sembada Surabaya, we can identify that the quality of the water meter tool is outside its control limits, so the quality of the water meter tool has not been controlled statistically.

4) DOB control charts are more sensitive than the control chart by $23.33 \%$. In the DOB control chart, there are 23 out of control data, whereas in the control chart there are 16 out of control data. This shows that DOB control charts are more precise in the process of quality control of the water meter tools at PDAM Surya Sembada Surabaya.

\section{REFERENCES}

[1] D. Montgomery, Introduction to statistical quality control. John Wiley \& Sons, 2007.

[2] K. Ishikawa, Introduction to quality control. Productivity Press, 1990.

[3] M. Nezhad, "Application of decision on beliefs for fault detection in uni-variate statistical process control," International Journal of Industrial Engineering, vol. 24, no. 4, pp. 297-305, 2013.

[4] M. Nezhad and S. Niaki, "A new monitoring design for uni-variate statistical quality control charts," Information Sciences, vol. 180, no. 6, pp. 1051-1059, 2010.

[5] H. Kume, Statistical Methods for Quality Improve-ment, Tokyo, The Association for Overseas Technical Scholarship. SPC and Continuous Improvement, by Mal Owen. New York: Springer-Verlag, 1989.

[6] D. Montgomery, Pengantar Pengendalian Kualitas Statistik. Yogyakarta: Gadjah Mada University, 1990.

[7] A. Fuady and M. Mashuri, "Pengendalian kualitas produksi botol rc cola $200 \mathrm{ml}$ di pt. iglas (persero) gresik menggunakan diagram kontrol dob (decision on belief)," Jurnal Sains dan Seni ITS, vol. 3, no. 2, pp. D254D259, 2014. 